\title{
MEDICATION ADHERENCE IN ELDERLY PATIENTS WITH HYPERTENSION
}

\author{
UMI ATHIYAH ${ }^{1 *}$, RIKA SUBARNIATI ${ }^{2}$, ANA YUDA ${ }^{1}$
}

${ }^{1}$ Department of Community Pharmacy, Faculty of Pharmacy, Universitas Airlangga, Surabaya, Jl. Dharmawangsa Dalam, Surabaya, Indonesia. ${ }^{2}$ Department of Health Promotion and Behavioral Sciences, Faculty of Public Health, Universitas Airlangga, Surabaya, Jl. Mulyosari, Surabaya, Indonesia. Email: umiathiyah@yahoo.com

Received: 10 April 2017, Revised and Accepted: 28 April 2017

\section{ABSTRACT}

Objective: This study aimed to identify the relationship between knowledge and beliefs about drugs with adherence of drug use based on the health belief model (HBM) theory.

Methods: Respondents were elderly hypertensive patients who received their medicine by prescription in one pharmacy in Surabaya. Knowledge and belief variables were measured by a validated questionnaire, while medication adherence was measured by pill count.

Results: There were 57 respondents aged $60-88$ years, $54.4 \%$ of which are female. A total of $57.9 \%$ of respondents used at least two kinds of antihypertension drugs and $54.4 \%$ had health problems other than hypertension. The results of Pearson analysis show that respondents' knowledge about the drug had a significant relationship with perceived threat, perceived benefit ( $p=0.043$ ), and perceived self-efficacy ( $p=0.015$ ), but no significant relationship with adherence, while the result of Spearman analysis shows that only perceived barrier had a significant relationship to adherence $(\mathrm{p}=0.029)$

Conclusion: To conclude, efforts to improve adherence was to lower perceived barrier which was primarily associated with decreased physical ability and concerns about the dangers of long-term drug use.

Keywords: Adherence, Health belief model, Elderly people, Hypertension.

(C) 2017 The Authors. Published by Innovare Academic Sciences Pvt Ltd. This is an open access article under the CC BY license (http://creativecommons. org/licenses/by/4. 0/) DOI: http://dx.doi.org/10.22159/ajpcr.2017.v10i8.19060

\section{INTRODUCTION}

The improvement of living standards and prosperity has an impact on the increasing life expectancy of the Indonesian people, resulting in a change in the proportion of the elderly population. In 2010, the elderly population was recorded at $7.56 \%$ of the entire population and is expected to increase to $11.83 \%$ in 2025 and $15.77 \%$ in 2035 , respectively [1]. The increasing impacts on the shift of health problems include the increased incidence of chronic and degenerative diseases, according to the results of the Basic Health Research 2013 [2].

The rising trend of pathological conditions among the elderly led to an increase in drug use, as shown in a study in Surabaya in 2012 involving 382 elderly respondents were $65.44 \%$ of respondents use at least two kinds of drugs, and $23.56 \%$ of respondents use five or more different drugs [3]. The use of various types of drugs with the different regimentation of the elderly can increase the risk of drugrelated problems including adverse reactions, drug interactions, toxic reactions, and nonadherence in drug use [4].

Adherence to drug use is one of the important components in achieving therapeutic goals. However, the drug therapy that has been defined by various pharmacological considerations, designed dosage forms, and latest technology formulation will not yield any benefits if the patient is not willing or not able to use the drug correctly. However, the incorrect use of drugs by a patient cannot merely be seen as the fault of the patient. The nonadherence of drug use involves many aspects that come from within or outside the will of the patient so that the process of using drugs is not merely a pharmacological process, but also a psychological, interpersonal, and social process [5]

In the elderly, no adherence can be fatal considering some physiological changes that occur as a result of the aging process. Those physiological changes impact the pharmacokinetics and pharmacodynamics of drugs, including the reduction in the proportion of bodily fluids that can increase the concentration of drug in the blood, a decrease in the production of several enzymes including metabolic enzymes, and decreased kidney function that affects the rate of drug elimination [6]. In these conditions, improper use of drugs may increase the risk of drug toxicity.

This study aimed to identify the adherence to antihypertensive medication use among the elderly in Surabaya with an approach based on the health beliefs model (HBM) theory. The selection of hypertensive patients as research subjects was based on the consideration that hypertension is a disease with a large number of cases in Indonesia and its prevalence increases among the elderly [2]. The asymptomatic nature of hypertension causes the adherence tends to be low. Meanwhile, a low adherence of drug use in hypertensive patients can accelerate the progression of the disease and organ damage that will increase morbidity and mortality, which in turn increase health expenses and health-care facilities $[7,8]$.

\section{METHODS}

\section{Respondents and research procedure}

Respondents in this study were elderly patients (aged 60 years or older) who obtained their antihypertensive drugs at one pharmacy in Surabaya, Indonesia, during the month of March 2015 using Indonesian National Health Insurance facilities. All patients who met the criteria were given informed consent. The data collection was performed at the patients' houses at the agreed time. There were 107 eligible patients; 27 patients were not found at the address recorded in the data pharmacies, 20 patients refused to be respondents, and 3 patients cannot continue to be the respondent in pill count to 2 due to death (1) and moving out of town (2), making the final group of respondents in this research were 57 patients. 


\section{The HBM measures}

A questionnaire was prepared based on a construct in the HBM theory developed by Rosenstock with modifications $[9,10]$ as shown in Fig. 1.

The variables measured were the patients' characteristics and knowledge about drugs (modifying factors). The belief in the drugs used (individual beliefs) includes the perceived threat, perceived benefits, perceived barriers, perceived self-efficacy, and the adherence of drug use (behaviors). The collection of data on the variables of knowledge and belief used a questionnaire that had been validated, while the variable of adherence was collected based on the observation list with pill count method.

The characteristics of respondents identified in this study were age, sex, latest degree of education, duration, and the condition of hypertension when first diagnosed, the number of antihypertensive medications used, and a number of other health problems. The hypertensive condition when first diagnosed was determined based on a classification according to JNC7 [11]. The information on the time and conditions of hypertension was based on information from the patient.

The variable of knowledge was compiled based on the Decree of the Minister of Health on the Standards of Pharmaceutical Services in Pharmacies [12]. Information to patients should be given to patients related to the drug used by those standards, including the name and purpose of use, rules of use, duration of use, undesirable effects and the means to resolve them, and how drugs were stored. There were 11 statements about their knowledge with a score of 1 to a "true" answer and 0 for a "false" or "not applicable" answer.

Belief in the drug use was measured using a Likert scale with a score of 1-5 in favorable statements and 5-1 to unfavorable statements. Perceived threat was defined as the patient's perception of the threat of hypertension when nonadherent in the use of drugs, which were translated into 5 statements describing two parameters, namely, the occurrence of complications and declining health conditions. Perceived benefit was defined as a patient's perception of the benefits of drug therapy and adherence in drug use (5 statements). Perceived barriers describe patients' perceptions of barriers to adhering to the use drugs that include the onset of undesirable effects, complex usage, and disruption of daily activities (6 statements). Perceived self-efficacy describes the patient's perception of their ability to adhere to the drug consisting of the ability to read the instructions, correct usage, and the punctuality of the time to take the medication (7 statements) [13]

\section{Medication adherence}

A counting of the drug in the patients' houses was performed 1 or 2 days after the last patient visit to the pharmacy to determine the amount of the baseline drug. The next visit was performed about 25 days after

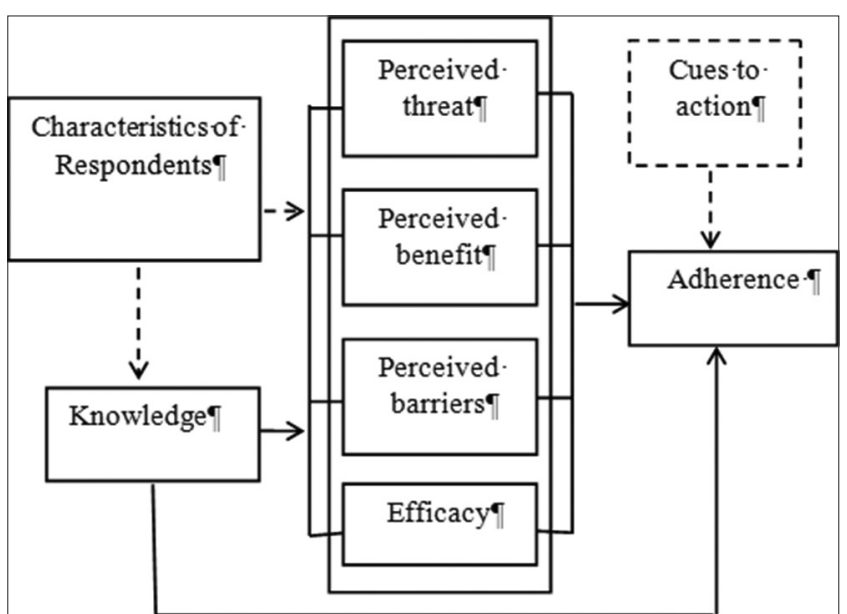

Fig. 1. The conceptual framework of the study the first visit to determine the remaining amount of the drug. The adherence to drug use is calculated based on drugs used by patients compared with drugs that are supposed to be used in the period of data collection. Patients were declared adherent if the calculation results of pill count were $\geq 70 \%$.

\section{Analysis}

The Pearson correlation test was used to see the relationship between belief and knowledge and Spearman to see the relationship between the knowledge and belief with the adherence of drug use.

\section{RESULTS AND DISCUSSION}

\section{Characteristics of respondents}

The characteristics of respondents can be shown in Table 1.

As shown in Table 1 the age range of respondents is between 60 and 88 years with an average age of respondents being 67.28 \pm 6.097 . Female respondents were more than male respondents. In Indonesia, the prevalence of hypertension in females tends to be higher than in males [2]. The education level of respondents ranged from elementary school dropout to college graduate. The total of 33 (57.9\%) of respondents were diagnosed with hypertension since $<10$ years ago. When first diagnosed, $39(68.4 \%)$ of respondents have had stage 2

Table 1: Characteristics of respondents

\begin{tabular}{|c|c|c|c|}
\hline No. & Characteristics & Criteria & n (\%) \\
\hline \multirow[t]{6}{*}{1} & Age (years) & $60-64$ & $21(36.8)$ \\
\hline & & $65-69$ & $16(28.1)$ \\
\hline & & $70-74$ & $13(22.8)$ \\
\hline & & $75-79$ & $6(10.5)$ \\
\hline & & $80-84$ & $0(0)$ \\
\hline & & $85-89$ & $1(1.8)$ \\
\hline \multirow[t]{2}{*}{2} & Gender & Male & $26(45.6)$ \\
\hline & & Female & $31(54.4)$ \\
\hline \multirow[t]{5}{*}{3} & Latest education & $\begin{array}{l}\text { Did not complete elementary } \\
\text { school }\end{array}$ & $1(1.8)$ \\
\hline & & Elementary school/equivalent & $7(12.3)$ \\
\hline & & Junior high school/equivalent & $12(21.1)$ \\
\hline & & High school/equivalent & $16(28.1)$ \\
\hline & & College & $21(36.8)$ \\
\hline \multirow[t]{3}{*}{4} & Hypertensive & Prehypertension & $2(3.5)$ \\
\hline & & Stage 1 hypertension & $16(28.1)$ \\
\hline & & Stage 2 hypertension & $39(68.4)$ \\
\hline \multirow[t]{7}{*}{5} & Duration of & $<5$ & $22(38.6)$ \\
\hline & & $5-9$ & $11(19.3)$ \\
\hline & & $10-14$ & $10(17.5)$ \\
\hline & & $15-19$ & $10(17.5)$ \\
\hline & & $20-24$ & $1(1.8)$ \\
\hline & & $25-29$ & $1(1.8)$ \\
\hline & & $30-34$ & $2(3.5)$ \\
\hline \multirow[t]{5}{*}{6} & Number of & 1 & $17(29.8)$ \\
\hline & & 2 & 33 (57.9) \\
\hline & & 3 & $5(8.8)$ \\
\hline & & 4 & $1(1.8)$ \\
\hline & & 5 & $1(1.8)$ \\
\hline \multirow[t]{5}{*}{7} & Number of other & 0 & $25(45.6)$ \\
\hline & & 1 & $19(31.6)$ \\
\hline & & 2 & $9(15.8)$ \\
\hline & & 3 & $2(3.5)$ \\
\hline & & 4 & $2(3.5)$ \\
\hline
\end{tabular}


hypertension with systolic blood pressure of $\geq 160 \mathrm{mmHg}$ and/or diastolic blood pressure of $\geq 100 \mathrm{mmHg}$. Hypertension is often called the "silent killer" due to its asymptomatic nature. The delay of the treatment occurs because people do not realize that their blood pressure has exceeded the normal blood pressure, while the common symptoms that often appear like headaches often can be treated with analgesics that can be obtained by self-medication [14]. A total of 33 (57.9\%) of respondents used two different antihypertensive drugs, and there were 7 (12.4\%) of respondents using 3-5 kinds of antihypertensive drugs. The treatment with one antihypertensive drug is highly recommended because it usually has a better adherence rate, has lower treatment costs, and also involves fewer risks of harmful drug effects than the combined use of several drugs [15]. A total of 32 (54.4\%) respondents had health problems besides hypertension. Most of these other health problems were diabetes and hyperlipidemia. Both of these conditions increase the risk of complications of hypertension and organ damages in the heart, kidney, and brain [15].

\section{Respondents' knowledge and beliefs about drugs}

The scores of respondents based on variables can be shown in Table 2 .

Table 2 was shown that the respondents' knowledge was quite high. The longer someone is having health problems; the information obtained regarding the issue tends to increase. Most respondents were able to recognize the antihypertensive drugs used and could refer exactly how many times a day and when the drug is used, but there were some of the respondents could not name the drug antihypertensive use. Such lack of knowledge is very risky since hypertensive patients should use the drug in the long term and are likely to have other health problems that have to be consulted to a different health service provider or perform selfmedication. The name of the drug is important to note so that they may mention again whenever a medical worker asks regarding the drugs routinely used. A large number of antihypertensive drugs alone or in various combinations are available, and physicians need to choose the most appropriate drug for a particular patient [16]. The medical worker can choose drugs that do not interact or commit a therapy duplication with the drug already administered [6].

The goal of the therapy of hypertension is to prevent deaths from the disease by inhibiting the progression of the disease with a target systolic blood pressure is $<150 \mathrm{mmHg}$ and diastolic blood pressure is $<90 \mathrm{mmHg}$ for the age of 60 years or more without diabetes and chronic kidney disease [15]. Some respondents (12 of 57) had false or lack of knowledge about those targets. The explanation on the matter is very important so that the respondent can recognize whether the therapeutic goal is reached or not during a routine inspection or self-blood pressure measurement at home. Achieving the goal of therapy will make the patient satisfied with the results of treatment, and it can provide a positive influence on the adherence of drug use [17]. A total of 10 out of 57 respondents considered that they only took antihypertensive medications when blood pressure rises or symptoms occur. It is very dangerous considering hypertension is often without symptoms, and the use of medication should be a routine to keep blood pressure stable as targeted. Efforts to prevent and treat hypertension through varieties of programs addressed to the associated problems should be continuously implemented including improvement of adherence to

Table 2: Scores of respondents based on variables

\begin{tabular}{lllll}
\hline No. & Variable & $\begin{array}{l}\text { Range of } \\
\text { possible } \\
\text { scores }\end{array}$ & $\begin{array}{l}\text { Range of } \\
\text { scores } \\
\text { in the } \\
\text { sample }\end{array}$ & \\
& & Mean \pm SD \\
\hline 1 & Knowledge & $0-11$ & $3-11$ & $8.11 \pm 2.249$ \\
2 & Perceived threat & $5-25$ & $11-25$ & $19.35 \pm 3.056$ \\
3 & Perceived benefit & $5-25$ & $15-25$ & $19.58 \pm 2.195$ \\
4 & Perceived barriers & $6-36$ & $6-23$ & $15.02 \pm 3.204$ \\
5 & Perceived self-efficacy & $7-35$ & $14-35$ & $27.47 \pm 3.185$ \\
\hline SD: Standard deviation & & &
\end{tabular}

prescribed medications provided to an individual hypertensive patient and lifestyle modifications which in turn reduce its complications, morbidities, and mortalities [18]. The irregular use of drugs will lead to treatment failure and increase the likelihood of organ damage and complications due to hypertension [15].

Nearly half of the respondents (27 of 57) had a perception that the use of the drug once a day means the drug can be used at any time as long as it is only consumed once a day. The interval of drug use is associated with $t_{1 / 2}$ of the drug so that the use drug with no fixed intervals can lead to the uncontrolled accumulation and fluctuation of drug levels in the blood so that they can increase the risk of toxic effects of the drug. In the elderly, the condition can be more dangerous with respect to drug pharmacodynamic changes due to aging, such as reduced body fluids and slowing of the rate of elimination [6].

On the measurement of perceived threat, most respondents felt that their hypertension could be severe and affect the future condition with respect to organ damage and costs to be incurred due to the nonadherent use of the drug. These results differ from other studies in which respondents felt that hypertension was an episodic, symptomatic disease, so antihypertensive medication was taken only when symptoms occur [19]. One's perception of health problems suffered was greatly influenced by the local culture and beliefs of the people around him/ her [17]. This means that the truth of the information is very important to encourage the formation of positive attitudes toward the problem.

Most respondents were sure that by adherently using drugs they could control their hypertension, but there were some respondents who feel that they only required drugs when symptoms occur such as headache and stiff neck. The adherence with drug use was strongly influenced by previous experience in the use of drugs [17]. Someone who had tried not to be adherent and did not experience meaningful losses in the form of pain or discomfort was likely to repeat nonadherence. It is feasible to do under conditions where disease and therapeutic success is not significantly experienced by the patient, so efforts to maintain the consistency of adherence are very important. Objectives and results of therapy which are clearly communicated will bring satisfaction to the therapy and provide a good experience on adherence so that they can strengthen the establishment of an adherence of drug use [20].

On the measurement of perceived barrier, most respondents felt that barriers to medication adherence were quite low, especially those that were related to physical barriers. Most respondents felt able to set up and use their own medicines. Barriers to adherence that often experienced by respondents were the concerns about the effects of long-term drug use and drug dependence. In the process of developing a new drug, advanced age is not a criterion in clinical testing, so that information about the safety of drugs on the elderly is also limited [6]. Some experts agreed that drug response in elderly is different with younger groups as a result of changes in the body due to aging. These conditions put the elderly as a group vulnerable to the incidence of drug side effects. Some respondents said that the continuous use of drugs would damage the kidneys. Basically, there are no drugs that are pharmacologically effective without causing harm, so consideration of the use of drugs has always been based on the ratio of benefits against the risks that can be posed by the drug use. On this basis, the health worker should explain that the possibility of kidney damage caused by hypertension that is not controlled is greater than that from the harmful effects of antihypertensive drugs used [15].

The belief of respondents to be able to adhere to use the drug in this study was very high, especially in terms of understanding the instructions and uses it properly. However, more than half of respondents were difficult to remember the medication schedule. This is probably due to a decline in cognitive functions due to aging. A simpler management of the therapy with small types of drugs used will lead to adherence [15]. The communication and cooperation between the pharmacist and the doctor who treated the patient is very important to resolve the matter. 
Pharmacists can play a role as conduits of information to doctors regarding several drug options that can be tailored to a patient's ability to adhere.

\section{The adherence of drug use}

Advanced age is a risk group for nonadherent use of the drug with respect to cognitive and motor abilities that began to decline. However, there were no studies that actually prove that the elderly are more nonadherent than the younger group. Elderly people usually adjust the schedule to take medication with daily activities, such as after breakfast, before going to bed every night, and so on, while the younger group is often overlooked because of the many activities taken during the duration of medication.

The results show that most respondents (73.3\%) adhered to the drug use. Respondents were able to follow instructions since the treatment of hypertension is a long-term therapy, and respondents have used drugs for a long time so that taking the drug has become a daily routine. In addition, there was still a good deal of awareness among respondents that with age the health problems will increase and that the use of drugs is needed to maintain the quality of life. However, there were suspicions that some respondents were hiding the medicine (pill-dumping) to give the impression of adherence that the drug has been consumed in appropriate amounts (white coat adherence)

Nonadherence could occur because the respondents use the drug more than instructed (overuse) or less than instructed (underuse) and could be caused by external and internal factors of the respondents. An example of external factors of overuse in this study was in drug services in pharmacy, the pharmacist provides drug products with different strengths compared to the required dose, and the respondents (patients) did not read the instructions carefully. It is also caused when respondents maintain excessive (double) drug use because the remainder of the drug from a previous visit and the drug given to the next visit bear different trade names, making respondents use both drugs simultaneously. The internal factors of overuse were respondents had completely forgotten that they have already taken the drug, ensuring the repeated use of the same drug. Underuse in the group of respondents of this study can occur because the respondents actually forget to take the drug, feel bored, and feel that they are already healed, and fear unwanted effects on long-term drug use.

The downside of measuring adherence with the pill count method is that the determination of adherence and nonadherence is simply based on the number of drugs used, while the timing, frequency, and interval of usage cannot be measured. The difference in these three aspects can significantly affect the clinical outcome [15].

\section{Relationships between variables}

The result of data analysis of the relationships between variables shown in Table 3.

Table 3 shows that the respondents' knowledge about drugs was related to the perception of the seriousness of the threat of disease progression if they were not adherent to drug use. Given that hypertension usually does not cause symptoms, the perceived threat was not pain that bothers a patient that encourages a person to take a drug.

Perceptions of threat development of the disease could be formed when patients are given education about hypertension, its risk factors, and potential complications that will occur due to the nonadherent use of the medicine, and they are explained that the purpose of the treatment of hypertension is not to cure the disease but to control blood pressure to prevent organ damage due to uncontrolled blood pressure [15].

Increasing knowledge can also lead to the increase of the belief of respondents on the benefits of adherence of the use of drugs as shown in Table 3. In some diseases that do not cause symptoms including hypertension, the benefits of medication cannot always be felt so that the wrong perception about the benefits of the drug can reduce the adherence of drug use. The role of pharmacists is essential to establish the motivation for elderly patients with hypertension to able to adhere to the therapy. The drug information is not merely about how to use the drug, but it should be more emphasized on the consequences of correct use to the development of the disease and the patients' quality of life.

The knowledge of respondents about the drug was also associated with their own beliefs to be able to adhere to the therapy. The results show that the instructions on the use of drugs are quite clear and easy to understand so that respondents believed that they could adhere to the instruction, but the elderly tend to be forgetful and confused with complicated and varying schedules to taking drugs. Pharmacists can help to make it easier to remember to take medication by providing readable time table schedules with larger text size, or give a medicine box that comes with the days and times to take drugs. The use of this medicine box is not only help respondents remember when to take the drug so that they do not miss (underuse), but also can prevent the respondents from taking double doses of drugs, where the condition (overuse) can be more dangerous among the elderly in connection with a reduction in the proportion of bodily fluids and the slowing of elimination rate due to aging.

Based on the Spearman analysis of correlation of knowledge with adherence to drugs, there were no significant relationships as shown in Table 4.

Meanwhile, during the test of the relationship between the beliefs of respondents about drug use with the adherence to drug use, it was found that belief in the HBM variable that is related to adherence to drug use was only perceived barrier with a correlation coefficient of -0.290 . The negative sign indicated that the association was inverse where higher perceived barrier means lower adherence. Atkinson said that the adherence established by patient preferences is the result of an analysis of the advantages and disadvantages of the intervention received, in this case, drug intervention [20]. Among this study's respondents, it was apparently the perceived barriers that had more influence on the decision to use drugs, mainly those related to the fear of drugs' side effects and the false perception regarding long-term drug use. Some studies also had similar results where the biggest obstacle for the elderly to adhere to therapy was the concern about side effects [21].

Eraker said that the patient's knowledge about the disease and treatment would affect the decision of the patient, but might not necessarily affect adherence [17]. This was consistent with the findings that knowledge was related to some belief variables (perceived threat, perceived benefits, and perceived self-efficacy), but not associated with adherence. The above description was in line with Horne who divides nonadherence into two categories: Intentional nonadherence and unintentional nonadherence [22]. Deliberate nonadherence is

Table 3: Pearson correlation test results

\begin{tabular}{lllllllll}
\hline Pearson correlation & \multicolumn{2}{l}{ Perceived threat } & \multicolumn{2}{c}{ Perceived benefit } & \multicolumn{2}{c}{ Perceived barriers } & & \multirow{2}{*}{ Perceived self-efficacy } \\
\cline { 2 - 9 } & significant & $\mathbf{r}$ & significant & $\mathbf{r}$ & significant & $\mathbf{r}$ & significant & r \\
\hline Knowledge & 0.000 & 0.522 & 0.043 & 0.269 & 0.261 & -0.151 & 0.015 & 0.319 \\
\hline
\end{tabular}


Table 4: Spearman correlation test results

\begin{tabular}{lll}
\hline Spearman correlation & \multicolumn{2}{l}{ Adherence } \\
\cline { 2 - 3 } & sig. & R \\
\hline Knowledge & 0.986 & -0.002 \\
Perceived threat & 0.701 & -0.052 \\
Perceived benefit & 0.224 & -0.157 \\
Perceived barriers & 0.029 & -0.29 \\
Perceived self-efficacy & 0.123 & -0.199 \\
\hline
\end{tabular}

usually associated with a low belief in treatment that makes patients not motivated to use the drug, whereas unintentional nonadherence is the result of the inability of patients to use the drug, usually linked to a decline in cognition and dexterity. Among this study's respondents, the majority of nonadherence cases in the use of drugs were caused accidentally. This was also evidenced by the results of research that adherence was related to the amount of drug used with a correlation coefficient of -0.302 in which the more drugs were used by patients; the less adherence tends to be. This result was also consistent with studies in other countries that the lack of adherence among the elderly was more often caused by accidents due to memory loss $[23,24]$ and the complexity of the regimentation of doses [25].

The main priority for intervention to improve adherence of drug use in populations with similar characteristics with this study was to lower the perceived or experienced barriers by improving the populations' ability to manage their own medicine. But considering that the capabilities are usually declining due to aging, the cooperation of the family or caregiver is indispensable for the success of the therapy. This statement does not mean that increased motivations by increasing the belief of patients are not required to improve adherence. Horne said that the quality of the relationship between health professionals and patients would increase the belief of patients to health professionals and interventions provided and ultimately would motivate patients to adhere [22]. The statement also applies to the elderly as proven by several studies [26]. Pharmacists as one of the most competent categories of health workers who understand the use of drugs has an obligation and a strategic position to promote the goals of therapy based on the pharmaceutical care $[27,28]$.

The limitation of this study was the division of adherent, and nonadherent categories were based on the previous studies linking adherence with the medical consequences of drug use that occurs in adult subjects with hypertension [29]. The consequences may be different in elderly subjects. In addition, the respondent criterion of the study was elderly people who use antihypertensive drugs of all active ingredients, while each of the active ingredients has different characteristics and might influence the respondents' experience of the benefits and side effects that can affect the respondent's decision to adhere.

\section{CONCLUSION}

There was a relationship between the respondents' knowledge about drugs with belief about the threat of the development of hypertension due to nonadherence when using drugs, belief about the benefits of adherence to drug use, and belief in respondents' ability to adhere to use drugs, although that belief was not related to the adherence to drug use. Knowledge of the drug also did not directly relate to the adherence to drug use. Only beliefs about barriers to adherent drug use were associated with adherence to drug use with a negative correlation coefficient. There needs to be necessary measures to minimize the obstacles for elderly patients to adhere, especially those related to concerns over the long-term drug use by providing correct information about medicines and improving the quality of the relationship with health professionals, especially pharmacists. Barriers in patients associated with reduced physical and cognitive abilities also need attention. Collaboration among health professionals, especially physicians and pharmacists, are needed to be determining the regimentation that is most precise and simplest by considering the patient's ability to adhere.

\section{REFERENCES}

1. Statistik BP. Proyeksi Penduduk Indonesia. Jakarta: Badan Pusat Statistik; 2013

2. Badan Penelitian dan Pengembangan Kesehatan Kementrian Kesehatan RI. Riset Kesehatan Dasar 2013. Jakarta: Kementrian Kesehatan Republik Indonesia; 2013.

3. Yuda A, Achmad GN, Nita Y. Drugs Used and Potential Drug Interaction in the Elderly. The $3^{\text {rd }}$ International Conference on Pharmacy and Advanced Pharmaceutycal Sciences. Yogyakarta: Faculty of Pharmacy Universitas Gadjah Mada; 2013. p. 170.

4. Chan DC, Chen JH, Kuo HK, We CJ, Lu IS, Chiu LS, et al. Drug related problems (DRPs) Identified from geriatric medication safety review clinic. Arch Gerontol Geriatr 2012;54(1):168-74.

5. Cipolle RJ, Strand L, Morley P. Pharmaceutical Care Practice: The Patient Centered Approach to Medication Management. $3^{\text {rd }}$ ed. New York: McGraw-Hill Companies, Inc.; 2012.

6. Midlov P, Eriksson T, Kragh A. Drug Related Problems in the Elderly. London, Dordrecht Heidenberg: Spinger; 2009.

7. Roebuck MC, Liberman JN, Gemmill-Toyama M, Brennan TA. Medication adherence leads to lower health care use and costs despite increased drug spending. Health Aff (Millwood) 2011;30(1):91-9.

8. Chowdhury R, Khan H, Heydon E, Shroufi A, Fahimi S, Moore C, et al. Adherence to cardiovascular therapy: A meta-analysus of prevalence and clinical consequences. Eur Heart J 2013;34:2940-8.

9. Champion VL, Skinner CS. The health belief model. In: Glanz K, Rimer BK, Vismanath K, editors. Health Behavior and Health Education. $4^{\text {th }}$ ed. San Francisco: Jossey-Bass; 2008. p. 45-65.

10. Rosenstock IM. Patients' adherence with health regimens. J Am Med Assoc 1975;234(4):402-3

11. James PA, Oparil S, Carter BL, Cushman WC, Dennison-Himmelfarb C, Handler J, et al. 2014 evidence-based guideline for the management of high blood pressure in adult: Report from the panel members appointed to the Eighth Joint National Committee (JNC 8). J Am Med Assoc 2014;311(5):507-20.

12. Kementrian Kesehatan RI. Peraturan Menteri Kesehatan Republik Indonesia No. 35 Tahun 2014 tentang Standar Pelayanan Kefarmasian di Apotek. Jakarta: Kementrian Kesehatan RI; 2014.

13. Kothari CR. Research Methodology: Methods and Techniques. $2^{\text {nd }}$ Revised Edition. New Delhi: New Age International Publisher; 2004.

14. Breaux-Shropshire TL, Brown KC, Pryor ER, Maples EH. Relationship of blood pressure self-monitoring, medication adherence, self-efficacy, stage of change, and blood pressure control among municipal workers with hypertension. Workplace Health Safety 2012;60(7):303-11.

15. Benowitz NL. Antihypertensive agents. In: Katzung BG, Masters SB, Trevor AJ, editors. Basic and Clinical Pharmacology. $12^{\text {th }}$ ed. Singapore: McGraw-Hill Companies, Inc.; 2012. p. 169-91.

16. Giri DR, Prasanna G, Chandrakanth P. Prescribing pattern of antihypertennsive drugs based on compelling indications with hypertension. Int J Pharm Pharm Sci 2016;8(2):72-5.

17. Eraker SA, Kirscht JP, Becker MH. Understanding and improving patient adherence. Ann Int Med 1984;100:258-68

18. Nasution A, Kharunnisa, Tanjung HR. Impacts of counseling on adherence to prescribed medcations and blood pressure of hypertensive patients in four indonesian primary health centers. Int J Pharm Pharm Sci 2015;7(3):114-7.

19. Buckley L, Labonville S, Barr JA. Systematic review of beliefs about hypertension and its tratment among African Americans. Curr Hypertens Rep 2016;18(7):52.

20. Atkinson MJ, Sinha A, Hass SL, Colman SS, Kumar RN, Brod M, et al. Validation of a general measure of treatment satisfactin, the treatment satisfaction questionnaire for medication (TSQM) using a national panel study of chronic disease. Health Qual Life Outcomes 2004;2(12):1-13

21. Krousel-Wood MA, Muntner P, Islam T, Morisky DE, Webber LS. Barrier to and determinants of medication adherence in hypertension management: Perspective of the cohort study of medication adherence among older adult. Med Clin N Am 2009;93:753-69.

22. Horne R. Adherence, adherence and Concordance. In: Taylor KM, editor. Pharmacy Practice. London: Taylor \& Francis; 2001. p. 148-66.

23. Park YH, Kim H, Jang SN, Koh CK. Predictors of adherence to 
medication in older Korean patients with hypertension. Eur J Cardiovas Nurs 2012;12(1):17-24.

24. Gadkari A, Mchorney CA. Unintentional nonadherence to chronic prescription medicatios: How unintentional is it really? BMC Health Serv Res 2012;12(98):1-12.

25. Tsai KT, Chen JH, Wen CJ, Kuo HK, Lu IS, Chiu LS, et al. Medication adherence among geriatric outpatients prescribed multiple medications. Am J Geriatr Pharmacother 2012;10(1):61-8.

26. Yap AF, Thirumoorthy T, Kwan YH. Medication adherence in the elderly. J Clin Gerontol Geriatr 2016;7:64-7.
27. Athiyah U. Model Asuhan Kefarmasian Pelayanan Obat Yang Diresepkan Dan Pengaruhnya Terhadap Perilaku Apoteker Dalam Asuhan Kefarmasian (Disertasi). Surabaya: Universitas Airlangga; 2007.

28. Ma C. A cross-sectional survey of medication adherence and associated factors for rural patients with hypertension. Appl Nurs Res 2016;31:94-9.

29. Gray SL, Mahoney JE, Blough DK. Medication adherence in elderly patients receiving home health services following hospital discharge. Geriatr Gerontol 2001;35:539-45. 